\title{
Role of Vacancy in Trapping Impurity of Nitrogen in Molybdenum
}

\author{
Liu Yuelin, Dai Zhenhong
}

Yantai University, Yantai 264005, China

\begin{abstract}
Employing the first-principles simulation combined with the statistical model, we have investigated the interplay between impurity of nitrogen $(\mathrm{N})$ and vacancy in molybdenum (Mo). Single $\mathrm{N}$ atom is energetically favorable for occupying the octahedral interstitial site. $\mathrm{N}$ atom is easily bonded at vacancy, and the trapping energy of $\mathrm{N}$ trapped by vacancy is $2.71 \mathrm{eV}$, in good agreement with the experimental result. Further, we predict vacancy concentration in the form of $\mathrm{N}_{1} \mathrm{~V}$ complex in Mo, which notably increases due to the presence of $\mathrm{N}$, despite the concentration of interstitial $\mathrm{N}$ is still higher than that of $\mathrm{N}_{1} \mathrm{~V}$ complexes. The results demonstrate the key role of vacancy in $\mathrm{N}$ trapping in Mo.
\end{abstract}

Key words: molybdenum; nitrogen; vacancy; trapping; first-principles

It is well known that the interaction of impurity atoms with metal exhibits broad technological implications in condensed matter physics scope ${ }^{[1-4]}$. Recently, a striking example is that metals are used as the first wall (FW) in a fusion reactor, in which impurity atoms is often present in FW. Correspondingly, exploring the interaction between impurity atoms and a metal FW can help us to well understand the effects of impurity on structure and properties of metals for a fusion reactor ${ }^{[5-12]}$. Nitrogen $(\mathrm{N})$ is generally the most frequent foreign impurity in the metal, and it is easily trapped by some extended defects such as vacancies, dislocations, and grain boundaries. At the same time, $\mathrm{N}$ can also trap the migrating vacancies so as to decrease the vacancy diffusion coefficient.

Molybdenum (Mo) is considered as one of the most promising FWs because of its low sputtering erosion and good thermal properties such as high thermal conductivity and high melting temperature. Generally, there is only a very small amount $\mathrm{N}$ in Mo; however, it has a crucial influence on the properties of Mo. Under irradiated condition, it is evident that impurity $\mathrm{N}$ plays a major role in the damage processes in metals such as ferritic steels due to the strong interactions of impurities with point defects ${ }^{[13]}$.
The N-metal systems ${ }^{[1,2,13-23]}$ are investigated extensively and used widely in a variety of industrial applications due to the well-known properties and fundamental importance. $\mathrm{N}$ impurities have been found to interact strongly with some metals such as ferritic steels ${ }^{[1,2,13]}, \mathrm{Mo}^{[18,19]}, \mathrm{V}^{[17,19]}, \mathrm{Ti}$, and $\mathrm{Zr}^{[14]}$. Among the nitrides, $\mathrm{W}$ nitrides $\left(\mathrm{WN}_{x}\right)$ have been extensively researched and received a lot of attention. Generally, the WN is considered as the ground-state structure which has a cubic cell with half of the octahedral site occupied with $\mathrm{W}$ atoms and the other half occupied with $\mathrm{N}$ atoms ${ }^{[21]}$. For Mo nitrides, the $\mathrm{Mo}_{2} \mathrm{~N}$ is a stable structure, in which the Mo-N bond length is $0.208 \mathrm{~nm}^{[24]}$. As to N-Mo studies, Hautala et al. ${ }^{[18]}$ have investigated the detrapping of helium and $\mathrm{N}$ from vacancies as well as $\mathrm{N}$ from helium-vacancy complexes in polycrystalline Mo. The dissociation energy of $\mathrm{N}$ from vacancy was measured to be $(2.5 \pm 0.2) \mathrm{eV}$. Subsequently, Filius et al. ${ }^{[20]}$ investigated the interaction between $\mathrm{N}$ and vacancies in Mo employing thermal helium desorption spectrometry (THDS). They confirmed the detrapping behavior of implanted helium and nitrogen in Mo from Hautala et al. and found that $\mathrm{N}$ atom has to overcome the detrapping energy of $(2.55 \pm 0.05)$ $\mathrm{eV}$ from a single vacancy in Mo. Also, more than one $\mathrm{N}$

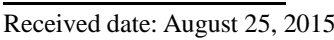

Foundation item: National Natural Science Foundation of China (51101135)

Corresponding author: Liu Yuelin, Ph. D., Associate Professor, Department of Physics, Yantai University, Yantai 264005, P. R. China, Tel: 0086-535-6902506, E-mail: liuyuelin@ss.buaa.edu.cn

Copyright (C 2016, Northwest Institute for Nonferrous Metal Research. Published by Elsevier BV. All rights reserved. 
atom have been observed in many small vacancy clusters to form $\mathrm{N}$-vacancy complexes, in which $\mathrm{N}$ atoms are stable up to the temperature of $1100 \mathrm{~K}$. Moreover, the present $\mathrm{N}$ atoms at vacancy can strongly increase the thermal stability of these $\mathrm{N}$-vacancy complexes.

However, in the studies mentioned above, only the implanted $\mathrm{N}$ impurity in Mo, i.e., higher $\mathrm{N}$ concentration case, was taken into account. Up to now, less work has been reported on the study of $\mathrm{N}$ as solid solution in Mo, especially for the low $\mathrm{N}$ concentration case. Correspondingly, the fundamental aspects underlying the interaction of $\mathrm{N}$ impurity with Mo remain not fully understood. In the present work, we thus investigate the interplay between $\mathrm{N}$ and vacancy in Mo using the first-principles simulations in combination with a statistical model.

\section{Methods}

Our first-principles calculations were performed using the Vienna Ab Initio Simulation Package (VASP) code ${ }^{[25,26]}$ based on the density functional theory (DFT). We used the generalized gradient approximation of Perdew and Wang ${ }^{\text {[27] }}$ and projector augmented wave potentials ${ }^{[28]}$ with a plane wave energy cutoff of $350 \mathrm{eV}$. During geometry optimization, a bcc-Mo supercell of 128 atoms was used with the side length of $1.264 \mathrm{~nm}$, and the Brillouin zone were sampled with $3 \times 3 \times 3 k$-points grid according to the Monkhorst-Pack scheme ${ }^{[29]}$. The calculated equilibrium lattice constant is $0.316 \mathrm{~nm}$ for body center cubic (bcc) Mo, in good agreement with the corresponding experimental value of $0.315 \mathrm{~nm}^{[30]}$. Both supercells size and atomic positions were relaxed to equilibrium, and energy minimization was converged until the forces on all the atoms were less than $10^{-3} \mathrm{eV} / 0.1 \mathrm{~nm}$.

The solution energy for $\mathrm{N}$ atom at interstitial sites in bulk Mo is defined as

$$
E^{\mathrm{S}}=E_{\mathrm{Mo}, \mathrm{N}}-E_{\mathrm{Mo}}-\mu_{\mathrm{N}} \text {, }
$$

Where, the $E_{\mathrm{Mo}, \mathrm{N}}$ is the total energy of the Mo supercell containing one $\mathrm{N}$ atom, $E_{\mathrm{Mo}}$ and $\mu_{\mathrm{N}}$ are the energy of an ideal Mo supercell and the $\mathrm{N}$ chemical potential, respectively.

The binding energy between $\mathrm{N}$ atoms and vacancy in Mo is defined by

$$
E_{\mathrm{N}_{\mathrm{l}} \mathrm{V}}^{\mathrm{b}}=\left[E_{\mathrm{Mo}, \mathrm{N}(\mathrm{O}-\text { site })}-E_{\mathrm{Mo}}\right]-\left[E_{\mathrm{Mo}, \mathrm{N}_{\mathrm{l}} \mathrm{V}}-E_{\mathrm{Mo}, \mathrm{V}}\right]
$$

where, $E_{\mathrm{Mo}, \mathrm{N}_{1} \mathrm{~V}}$ and $E_{\mathrm{Mo}, \mathrm{V}}$ are the energies of the Mo supercell with one $\mathrm{N}$ atom at vacancy and only one pure

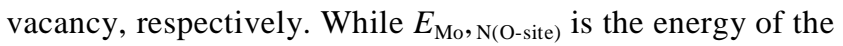
Mo supercell with an octahedral interstitial site (O-site) $\mathrm{N}$ atom. Here, negative binding energy indicates repulsion between per $\mathrm{N}$ atom and vacancy, while positive value indicates attraction.

The trapping energy of $\mathrm{N}$ atom by vacancy can be usually approximated as the binding energy summed with the diffusion (migration) energy barrier of $\mathrm{N}$ atom in bulk Mo, i.e.,

$$
E_{\mathrm{N}}^{\text {trap }}=E_{\mathrm{N}_{\mathrm{n}} \mathrm{V}}^{\mathrm{b}}+E_{\mathrm{N}}^{\mathrm{m}}
$$

\section{Results and Discussion}

First, the stabilities of $\mathrm{N}$ are examined at the interstitial sites. According to the present first-principles calculation, the $\mathrm{N}$ chemical potential is $-8.31 \mathrm{eV}$. With this value as a reference point, a single $\mathrm{N}$ atom is shown to be energetically favorable to occupy the O-site with lower solution energy of $0.796 \mathrm{eV}$ compared with $1.511 \mathrm{eV}$ at the tetrahedral interstitial site (T-site). At the same time, we find that $\mathrm{N}$ atom always moves towards the $\mathrm{O}$-site after the optimization of the structure if it is slightly shifted from the T-site. This result indicates that T-site is only a local saddle point position instead of the local energy minimum site, similar to the behaviors of $\mathrm{N}$ in other bcc metals such as $\alpha-\mathrm{Fe}^{[1]}$. Kinetically, the optimal diffusion path for interstitial $\mathrm{N}$ atom is that $\mathrm{N}$ jumps from an $\mathrm{O}$-site to another $\mathrm{O}$-site via a mediate transition state $\mathrm{T}$-site $(\mathrm{O} \rightarrow \mathrm{T} \rightarrow \mathrm{O}$ path $)$ in bcc Mo. The corresponding diffusion energy barrier can be calculated using the climbing image nudged elastic band (CI-NEB) method ${ }^{[31]}$, and its value is $0.71 \mathrm{eV}$, much smaller than that of the result $(2.29 \mathrm{eV})$ measured by Wert and $\mathrm{Marx}^{[32]}$ from the temperature of the internal friction peak. Such a large discrepancy with the results reported in Ref.[32] is puzzling to us only because the difference in methods is that they used "the internal friction peak" and we used the CI-NEB. Apparently, a more complete scrutiny of $\mathrm{N}$ energy barrier is desirable in the future. Recently, Domain et al. calculated the energy barrier of $\mathrm{N}$ in $\alpha$-Fe using the first-principles method ${ }^{[1]}$. They obtained an energy barrier of $0.77 \mathrm{eV}$, little higher than $0.71 \mathrm{eV}$ for $\mathrm{N}$ in Mo. The possible reason might be that Mo has a larger lattice constant so as to make $\mathrm{N}$ atom migratation easier in Mo than in $\alpha$-Fe.

Next, we investigated the $\mathrm{N}$ trapping behaviors in a monovacancy. According to Eq.(2), the calculated results show that $\mathrm{N}$ and vacancy exhibit a strong binding with a large binding energy of $2.00 \mathrm{eV}$. Moreover, $\mathrm{N}$ can not occupy vacancy center, but stay at an leaving- vacancycenter site $(\sim 0.136 \mathrm{~nm}$ from the vacancy-center $)$ approaching to an O-site (Fig.1). Also, there are six equivalent most stable positions close to the O-sites near the vacancy-center, as indicated in Fig.1. After establishing the binding energy of $\mathrm{N}$ with vacancy, we can further determine the trapping energy of $\mathrm{N}$ in Mo in terms of Eq. (3). The trapping energy of $\mathrm{N}$ trapped by vacancy is $2.71 \mathrm{eV}$, in good agreement with the experimental result of $(2.55 \pm$ $0.05) \mathrm{eV}^{[20]}$. Here we have to mention the migration energy of $\mathrm{N}$ atom at interstitial site again. Wert et al. ${ }^{[33]}$ obtained 


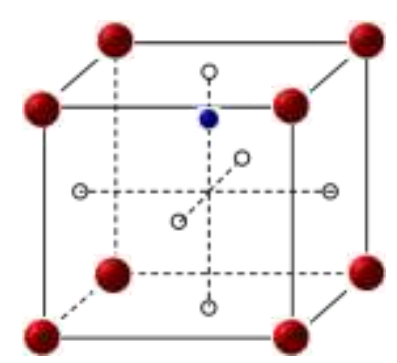

Fig.1 Optimal site for $\mathrm{N}$ binding at monovacancy (the circles mark the 6 O-sites, the smaller blue and larger red balls represent $\mathrm{N}$ and Mo atoms, respectively)

an energy barrier of $2.29 \mathrm{eV}$ from the temperature of the internal friction peak. If the energy barrier is really $2.29 \mathrm{eV}$, the trapping energy of $\mathrm{N}$ at vacancy should be $4.29 \mathrm{eV}$, far away from the experimental value of $(2.55 \pm 0.05) \mathrm{eV}$.

According to the above results, it is important to note that as long as $\mathrm{N}$ atom jumps into the vacancy, it will have to overcome a larger detrapping energy to go back to bulk interstitial site. Therefore, it is impossible for $\mathrm{N}$ to escape away from the vacancy due to the larger detrapping energy of $2.71 \mathrm{eV}$. The possible reason for $\mathrm{N}$ exhibiting a much larger trapping energy at vacancy might be that $\mathrm{N}$ deviates from the vacancy center to bond with the neighboring Mo atom through a N-Mo bonding physical mechanism. The $\mathrm{N}$ atom can be found to form the covalent-like bond with the first nearest-neighbor Mo atom. The corresponding bond length is $0.2 .05 \mathrm{~nm}$, in good agreement with the experimental value of $0.208 \mathrm{~nm}^{[24]}$.

Finally, we quantify the concentrations of vacancy-like defects related to impurity $\mathrm{N}$ in Mo. In terms of the Boltzmann distribution, the concentration of $\mathrm{N}$ atoms per unit volume, $n_{j}^{\mathrm{N}}$ in a particular region (site) $j$ is related to the site energy $E_{j}^{\mathrm{N}}$ as

$$
n_{j}^{\mathrm{N}}=\frac{A_{\mathrm{N}} A}{Z} \mathrm{e}^{-E_{j}^{\mathrm{N}} / k T}
$$

where, $j$ runs over the whole Mo lattice of a total number of $A$ sites, which include the vacancy vicinity, indicated as $A_{\mathrm{V}}$ with the binding energies of impurity $\mathrm{N}$, and those far away from the vacancy, indicated as $A_{\mathrm{Mo}}$ with solution energy of $\mathrm{N}$ at the $\mathrm{O}$-site. $A_{\mathrm{N}}$ represents the total $\mathrm{N}$ atom number. $k$ is the Boltzmann constant and $T$ is the absolute temperature. $Z$ represents the partition function written as

$$
Z=\sum_{j} A_{j} \mathrm{e}^{-E_{j}^{\mathrm{N}} / k T}=A_{\mathrm{V}} \mathrm{e}^{-E_{\mathrm{V}}^{\mathrm{N}} / k T}+A_{\mathrm{Mo}} \mathrm{e}^{-E_{\mathrm{Mo}}^{\mathrm{N}} / k T}
$$

So, the ratio of $\mathrm{N}$ concentration in the vacancy vicinity and bulk regions is given as:

$$
\frac{n_{\mathrm{V}}^{\mathrm{N}}}{n_{\mathrm{Mo}}^{\mathrm{N}}}=\frac{A_{\mathrm{V}}}{A_{\mathrm{Mo}}} \mathrm{e}^{-\left(E_{\mathrm{V}}^{\mathrm{N}}-E_{\mathrm{Mo}}^{\mathrm{N}}\right) / k T}=\frac{A_{\mathrm{V}}}{A_{\mathrm{Mo}}} \mathrm{e}^{E_{\mathrm{N}}^{\mathrm{bind}} / k T}
$$

where, $n_{\mathrm{V}}^{\mathrm{N}}$ and $n_{\mathrm{Mo}}^{\mathrm{N}}$ are the $\mathrm{N}$ atom number per unit volume in the vacancy vicinity and the bulk region, respectively. $A_{\mathrm{V}}$ and $A_{\mathrm{Mo}}$ are the total number of vacancy and Mo atoms at the given temperature, respectively. $E_{\mathrm{N}}^{\text {bind }}$ is the $\mathrm{N}$ binding energy in vacancy. According to Eq.(6), we note that $A_{\mathrm{V}} / A_{\mathrm{Mo}}$ is the vacancy concentration $c_{\mathrm{V}}$ in Mo. The vacancy concentration $c_{\mathrm{V}}$ in metals can be roughly given as:

$$
c_{\mathrm{V}}=\mathrm{e}^{-E_{\mathrm{V}}^{\mathrm{f}} / k T}
$$

where, $E_{\mathrm{V}}^{\mathrm{f}}$ is the vacancy formation energy. According to the present calculation, it is $2.59 \mathrm{eV}$, in good agreement with the reported value $2.7 \sim 3.24 \mathrm{eV}$ examined experimentally using resistivity method ${ }^{[34]}$. Then, combining Eq.(7) and Eq.(6), we can estimate the ratio $n_{\mathrm{V}}^{\mathrm{N}} / n_{\mathrm{Mo}}^{\mathrm{N}}$ at the typical experimental irradiating temperatures of 300 1000 $\mathrm{K}^{[32,35]}$ in Mo as the following formula:

$$
\frac{n_{\mathrm{V}}^{\mathrm{N}}}{n_{\mathrm{Mo}}^{\mathrm{N}}}=\mathrm{e}^{-E_{\mathrm{V}}^{\mathrm{f}} / k T} \cdot \mathrm{e}^{E_{\mathrm{N}}^{\mathrm{bind}} / k T}
$$

As plotted in Fig.2, the $\mathrm{N}$ atom number trapped by vacancy is obviously lower than that at the bulk regions in Mo, suggesting that impurity $\mathrm{N}$ mainly distribute in the interstitial sites. Such phenomenon is similar to the distribution of impurity carbon in $\alpha-\mathrm{Fe}^{[36,37]}$.

We now turn our attention to calculating the concrete concentration of $\mathrm{N}$ trapped by vacancy. In order to make comparison, we also estimate the interstitial $\mathrm{N}$ and total vacancy concentrations in Mo. For interstitial $\mathrm{N}$ atom, the equilibrium defect distribution in the multi-component system can be described from the grand canonical ensemble. In the low concentration limit, the interstitial impurity concentration at a given temperature is determined by the following equation:

$$
C_{\text {impurity }}=A_{\text {sites }} A_{\text {configuration }} \exp \left(-E_{\text {impurity }}^{\mathrm{s}} / k T\right)
$$

where, $A_{\text {sites }}$ is the number of lattice sites (or the number of interstitial sites per solution atom) on which the defect can

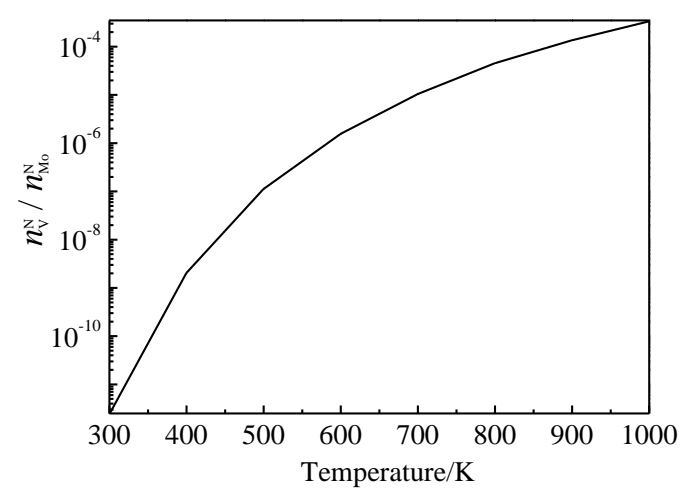

Fig.2 Ratio of $\mathrm{N}$ atoms trapped by vacancy over those in the intrinsic region in Mo as function of temperature 
be incorporated per unit volume, and $A_{\text {configuration }}$ is the number of equivalent configurations per site. Such a modeling method has been successfully applied to determine the concentration of impurity in metal system ${ }^{[38]}$. For the present N-Mo system, $A_{\text {configuration }}$ is taken as 1 because the symmetry breaking does not occur. While the $A_{\text {sites }}$ is taken as $3 / 2$ due to the ratio of $A_{\text {sites }} / A_{\text {configuration, }}$ i.e., $\mathrm{N}$ atom occupies the $\mathrm{O}$-site in bcc Mo. Thus, the interstitial $\mathrm{N}$ concentration can be expressed as follows:

$$
C_{\mathrm{N}}=3 / 2 \exp \left(E^{\mathrm{S}}{ }_{\mathrm{N}} / k T\right)
$$

Using the calculated $\mathrm{N}$ solution energy of $0.796 \mathrm{eV}$ at the $\mathrm{O}$-site, we give the solution concentration of $\mathrm{N}$ in bulk Mo. Fig. 3 shows the concentration of $\mathrm{N}$ in the bulk Mo as a function of temperature with respect to the unit of the atomic fraction of $\mathrm{N}(\mathrm{N} / \mathrm{Mo})$. One can see that there exists a relatively lower $\mathrm{N}$ interstitial concentration in bulk Mo when the temperature is below $800 \mathrm{~K}$. Also, the solubility of $\mathrm{N}$ in intrinsic Mo strongly depends on the temperature and increases notably with the increasing of temperature. The concrete concentration values of $\mathrm{N}$ at interstital site in $\mathrm{W}$ can be increased by 4 orders of magnitude from $400 \mathrm{~K}$ to $1000 \mathrm{~K}$. This implies that there exists a strong endothermic reaction for the $\mathrm{N}$ solution in Mo. Because few experimental or relevant calculation data can be found, here we again provide a quite useful reference to quantitatively understand the solution properties of $\mathrm{N}$ in intrinsic bulk Mo.

The total vacancy concentration is approximately estimated according to the below expression:

$$
c_{\mathrm{V}}^{T}=c_{\mathrm{V}}+c_{\mathrm{N}_{1} \mathrm{~V}}
$$

where, $c_{\mathrm{V}}$ is the pure vacancy concentration, i.e., the vacancy does not contain $\mathrm{N}$ atom, while $c_{\mathrm{N}_{1} \mathrm{~V}}$ represents the vacancy concentration with one $\mathrm{N}$ atom case. Note that there might be other $\mathrm{N}_{n} \mathrm{~V}(n=2,3,4, \ldots)$ complexes in Mo, however, we assume that $\mathrm{N}_{1} \mathrm{~V}$ is the main complex due to

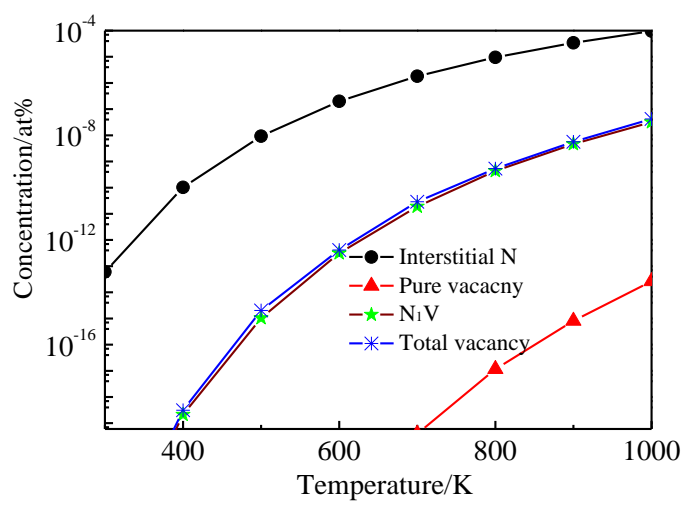

Fig.3 Concentrations of interstitial $N$, pure vacancy, and $\mathrm{N}_{1} \mathrm{~V}$ complex in Mo as a function of temperature the low $\mathrm{N}$ concentration case in the present study. Moreover, the stability of vacancies containing large numbers of $\mathrm{N}$ atoms is coherent with thermodynamics only at very low temperature. In the Grand Canonical ensemble, at room or higher temperature, the Mo or other metal system creates more vacancies, containing less $\mathrm{N}$ atoms. Then, $\mathrm{N}$ should distribute uniformly at the vacancies to only form $\mathrm{N}_{1} \mathrm{~V}$ complexes instead of gathering into a monovacancy to form $\mathrm{N}_{3} \mathrm{~V}$ or $\mathrm{N}_{4} \mathrm{~V}$ complexes at the low $\mathrm{N}$ concentration case.

The whole results are illustrated in Fig.3. Although the $\mathrm{N}$ atom number trapped by vacancy is lower than that at the bulk region, it is clear to see that the presence of $\mathrm{N}$ can increase the vacancy concentration from $1.16 \times 10^{-17}$ at $\%$ to $5.33 \times 10^{-10}$ at $\%$ at $800 \mathrm{~K}$, i.e., vacancy concentration can be increased by 7 orders of magnitude. Therefore, we can conclude that more vacancies are produced due to the presence of impurity $\mathrm{N}$ atoms. This demonstrates that $\mathrm{N}$ can enhance the vacancy formation in the form of $\mathrm{N}_{1} \mathrm{~V}$ complexes in Mo.

\section{Conclusions}

1) In bulk Mo, a single $\mathrm{N}$ atom is energetically favorable for occupying the octahedral interstitial site. $\mathrm{N}$ atom can be easily bonded at a vacancy with the binding energy of 2.00 $\mathrm{eV}$. The trapping energy of $\mathrm{N}$ at vacancy is $2.71 \mathrm{eV}$, in good agreement with the experimental result.

2) We predict vacancy concentration in form of $\mathrm{N}_{1} \mathrm{~V}$ complex, which notably increases due to the presence of $\mathrm{N}$, despite the concentration of interstitial $\mathrm{N}$ is still higher than that of $\mathrm{N}_{1} \mathrm{~V}$ complexes in Mo.

3) The vacancy play a key role in the $\mathrm{N}$ trapping in Mo, which will provide a useful reference for the design and preparation of Mo as the first-wall in the future fusion reactors.

\section{References}

1 Domain C, Becquart C S, Foct J. Physical Review B[J], 2004, 69: 144112

2 Little E A, Harries D R. Metal Science Journal[J], 1970, 4: 188

3 Zhou H B, Liu Y L, Zhang Y et al. Nuclear Fusion[J], 2010, 50: 025016

4 Liu Y L, Zhou H B, Jin S et al. Journal Physics: Condensed Matter[J], 2010, 22: 445504

5 Causey R, Wilson K, Venhaus $\mathrm{T}$ et al. Journal Nuclear Materials [J], 1999, 266-269: 467

6 Zhou H B, Liu Y L, Zhang Y et al. Nuclear Fusion[J], 2010, 50: 025016

7 Li W Y, Zhang Y, Zhou H B et al. Nuclear Instrument Methods Physics Research Section B[J], 2011, 269: 1731

8 Zhou H B, Jin S, Zhang Y et al. Physical Review Letters[J], 2012, 109: 135502

9 Li X C, Shu X, Liu Y N et al. Journal Nuclear Materials[J], 
2012, 426: 31

10 Li X C, Gao F, Lu G H. Nuclear Instrument Methods Physics Research Section B[J], 2009, 267: 319

11 Li X C, Shu X, Liu Y N et al. Journal Nuclear Materials[J], 2011, 408: 12

12 Luo G N, Umstadter K, Shu W M et al. Nuclear Instrument Methods Physics Research Section B[J], 2009, 267: 3041

13 Little E A. International Metal Review[J], 1976, 204: 25

14 Ruban A V, Baykov V I, Johansson B et al. Physical Review $B[\mathrm{~J}], 2010,82: 134110$

15 Felton S, Cann B L, Edmonds A M et al. Journal Physics: Condensed Matter[J], 2009, 21: 364212

16 Cruz M M, Silva R C, France Net al. Journal Physics: Condensed Matter [J], 2009, 21: 206002

17 Yamanaka S, Kashiwara Y, Sugiyama H et al. Journal Nuclear Materials[J], 1997, 247: 244

18 Hautala M, Anttila A, Hirvonen J. Journal Nuclear Materials[J], 1982, 105: 172

19 Kainuma T, Iwao N, Suzuki $\mathrm{T}$ et al. Journal Nuclear Materials[J], 1979, 80: 339

20 Filius H A, Van Veen A. Journal Nuclear Materials[J], 1987, 144: 1

21 Choi D, Kumta P N. Journal of American Ceramal Society[J], 2007, 90: 3113

22 Toth L E. In: Margrave J L ed. Transition Metal Carbides and Nitrides Vol. 7[M]. New York: Academic Press, 1971: 296
23 Jhi S H, Ihm J, Louie S G et al. Nature[J], 1999, 399: 132

24 Chen J G. Chemical Review[J], 1996, 96: 1477

25 Kresse G, Hafner J. Physical Review B[J], 1993, 47: 558

26 Kresse G, Furthmüller J. Physical Review B[J], 1996, 54: 11 169

27 Perdew J P, Wang Y. Physical Review B[J], 1992, 45: 13244

28 Blochl P E. Physical Review B[J], 1994, 50: 17953

29 Monkhorst H J, Pack J D. Physical Review B[J], 1976, 13 : 5188

30 Kittel C. Introduction to Solid State Physics, 7th ed[M]. New York: Wiley, 1996

31 Wert C, Zener C. Physical Review[J], 1949, 76: 1169

32 Wright G M, Whyte D G, Lipschultz B. Journal Nuclear Materials[J], 2009, 390-391: 544

33 Wert C, Marx J. Acta Metalialia [J], 1953, 1: 113

34 Kraftmakher Y. Physical Review[J], 1998, 299: 79

35 Hoshihira T, Otsuka T, Tanabe T. Journal Nuclear Materials[J], 2009, 390-391: 1029

36 Fu C C, Meslin E, Barbu A et al. Solid State Phenomena[J], 2008, 139: 157

37 Forst C J, Slycke J, Van Vliet K J et al. Physical Review Letters[J], 2006, 96: 175501

38 Van de Walle C G, Neugebauer J. Journal Applied Physics[J], 2004, $95: 3851$

\title{
钼中空位在杂质氮捕获中的作用
}

\author{
刘悦林，戴振宏 \\ (烟台大学, 山东 烟台 264005)
}

\begin{abstract}
摘 要: 应用第一原理结合统计模型的方法, 研究了钿中杂质氮与空位的相互作用。单个氮原子易于占据八面体间隙位。杂质氮很容易 为空位所捕获, 其捕获能为 $2.71 \mathrm{eV}$, 与实验值一致。计算了与氮有关的点缺陷浓度, 结果表明以 $\mathrm{N}_{1} \mathrm{~V}$ 复合物形式存在的空位浓度明显增 加, 钿中空位在杂质氮的捕获中起到了关键的作用。
\end{abstract}

关键词: 钿; 氮; 空位; 捕获; 第一原理

作者简介: 刘悦林, 男, 1980 年生, 博士, 副教授, 烟台大学物理系, 山东 烟台 264005, 电话: 0535-6902506, E-mail: liuyl@ytu.edu.cn 